\title{
Classroom Management Strategies of Multigrade Schools with Emphasis on the Role of Technology
}

\author{
Taraneh Enayati, ${ }^{1}$ Farshideh Zameni,, ${ }^{1,}$ and Mousa Movahedian ${ }^{2}$ \\ ${ }^{1}$ Assistant Professor, Department of Educational Management, Sari Branch, Islamic Azad University, Sari, IR Iran \\ ${ }^{2}$ Department of Educational Technology, Sari Branch, Islamic Azad University, Sari, IR Iran \\ "Corresponding author: Farshideh Zameni, Assistant Professor, Department of Educational Management, Sari Branch, Islamic Azad University, Sari, IR Iran, E-mail: \\ f_zameni@yahoo.com
}

Received 2016 January 05; Revised 2016 June 14; Accepted 2016 June 29.

\begin{abstract}
Introduction: It appears that the effectiveness of a multigrade school class is dependent on the type of class management. Therefore this study aims to determine the classroom management strategies in multigrade schools with emphasis on the role of technology in Mazandaran province of Iran.

Methods: The research was a descriptive survey. The statistical population consisted of multigrade school teachers in the eastern part of Mazandaran province, including 129 people of whom 97 were chosen as the subjects of the study based on Krejcie and Morgan's table. A questionnaire with the reliability of 0.90 was used for data collection. Factor analysis was used to analyze the data via SPSS 22.

Results: The results revealed that KMO measure of sampling adequacy was $0.711(\mathrm{sig}=0.000)$. Also, results revealed that ten strategies can be employed to explain total Variance of managing multigrade classes: Using classroom spaces (9.884), flexibility (8.283), application of software and hardware technologies (7.551), organizing learning environment (7.497), evaluation (7.103), appropriate teaching methods (7.034), educational tools (6.144), delegation of authority (5.970), teachers' professional experiences (4.851), and enlivening the learning environment (4.562).

Conclusions: In order to implement the policy of education for all, multigrade schools should be considered as an opportunity. Therefore applying educational technology is one of the effective ways to manage these kinds of classrooms so as to facilitate learning and improve performance in the classrooms of multigrade schools.
\end{abstract}

Keywords: Schools, Primary Schools, Multigrade Schools, Classroom Management, Strategy, Educational Technology

\section{Introduction}

At a point, multigrade teaching is an important and appropriate means of helping nations in attaining their internationally-mandated Education for All targets and national millennium development goals by providing good quality education to children who are often neglected by their education system since they live in small, poor, and remote communities. More importantly, it is an approach that can help schools in these communities and teachers in these schools serve their students better by providing them an education that is both of good quality and relevant to the community in which they live. Many teachers in Asia and the Pacific need to teach students from more than one grade in one classroom. And many in Cambodia, China, India, Indonesia, the Philippines, Vietnam and elsewhere are already doing so. The approach being used is known as multigrade teaching-teaching classes of students not only of different ages and abilities but also at different grade levels (1).

Multigrade teaching refers to the teaching of students of different ages, grades and abilities in the same group.
It is referred to variously as 'multilevel', 'multiple class', 'composite class', 'vertical group', 'family classes', and, in the case of one-teacher schools, 'unitary schools' in the literature. It is to be distinguished from mono-grade teaching in which students within the same grade are assumed to be more similar in terms of age and ability. However, substantial variation in ability within a grade often results in 'mixed-ability' teaching (2).

Multigrade schooling is a strategy which can be used to improve the educational prospects of children in conditions where a teacher for each grade of primary school is impractical as a result of the limited size of the student population. In a multigrade school, teachers manage two or more classes simultaneously and a single teacher may be responsible for all primary grades. Multigrade schooling is employed in isolated rural areas of both developed and developing countries (3).

There are three important rationales behind the likely occurrence of multigrade teaching in both developed and developing countries:

Firstly, multigrading is often associated with small 
schools in remote and sparsely populated areas. In such schools, there may be only one, two or three teachers, however they offer a complete cycle of primary education, as a result, each of these teachers must deal with multigrade classes. These 'small' schools are also sometimes referred to as multigrade schools. Multigrade schools have gained attention in the developing country context due to their ability of increasing primary school participation rates. More children, particularly females are being encouraged into school by bringing the school closer to the community.

Secondly, multigrade teaching is also common in larger urban and suburban schools. In some countries, it is a response to uneven student enrollment. For instance, a school with a two and a half grade entry may have to combine two grade levels to make up class sizes. Also, in countries where teachers absenteeism is high, and there is no cover, grades may be combined to avoid having a class with no teacher present in it. A single teacher then has to handle two grade level groups together.

Thirdly, multigrade teaching may be a deliberate response to educational problems. In developed countries, this is associated to the multiage perspective. Proponents of mixed age grouping claim that there are sound pedagogical reasons for placing students of different ages together in the same classroom. It is claimed that mixed age classes stimulate children's social development and encourage greater classroom cooperation. These arguments are seldomly mentioned in the literature of developing country, although several commentators are of the view that multigrade organized classes are potentially a cost effective means of providing quality education which is difficult to get to these areas (4).

Several conditions which brought about multigrade teaching in schools: (i) Schools in areas of low population density where schools are widely scattered and inaccessible and enrolment is low; (ii) Schools that consist of a cluster of classrooms in different locations, in which some classes are multigrade for the same reasons as (i), and some are monograde; (iii) Schools in areas of population decline, where there was formerly monograde teaching, and now, only a small number of teachers are employed in the schools, necessitating multigrade teaching; (iv) Schools in areas of population growth and school expansion, where enrolments in the expanding upper grades continue to be small; (v) Schools in areas where parents send their children to more popular schools within reasonable travel distance, resulting in a decline in the number of students and teachers in the less popular school; (vi) Schools in which the official number of teachers deployed justifies monograde teaching but where the actual number deployed is less. The inadequate deployment arises for a number of reasons including low teacher supply, teachers who are posted to a school but do not report for duty, or teachers on medical or casual leave; (vii) Schools in which the number of students admitted to a class include more than one class group, necessitating a combination of some of the students with those in a class group of different grade; (viii) Schools in which teacher absenteeism is high and the organizations of supplementary teacher are ineffectual or non-existent; (ix) Schools in which teachers for pedagogic reasons have decided to organise students in multigrade rather than monograde groups, often as part of a more general reform of the education system (5).

The positive impact of multigrade teaching: Associated benefits of multigrade teaching are impact on orphans; reduced gender disparity; overall improvement in educational experience; and social gains (6). Also, little positive impacts of multigrade teaching are listed below:

- Expansion of Access: For millions of children globally, the only type of school to which they will gain access, if at all they wil gain access will be multigraded. Economically and socially disadvantaged areas include disproportionate numbers of multigraded schools. In many disadvantaged and marginalised contexts the fundamental educational issue is not if a school is multigraded or monograded but if there is presence of a school. Cognitive achievement effects on learners: Veenman's in 1995 review of studies mainly from OECD countries distinguished achievement results in different types of mono and multigrade class (i) multigrade, formed out of necessity, from imbalanced or inadequate enrolments; (ii) single-grade and (iii) multiage, non graded, formed for pedagogical or philosophical reasons. He found no fact to suggest that learning in multigrade or multi-age classes was inferior to that in monograde classes.

- Social and personal learning effects on learners: Many studies that variously addressed children's friendships, self concepts, altruism and attitude to school. Generally, the socio-emotional development of learners in multigrade groups is either accelerated or showed no difference, when compared with learners in monograde groups. And reports revealed positive and negative findings on the reduction of anxiety levels, the maturity of friendship patterns and personal and social adjustment and positive findings on self concept, self esteem, and attitudes to $\operatorname{school}(7)$.

International recognition of the benefits of multigrade teaching: The centre for multigrade education (CMGE) was established in 2009 through a grant from the Dutch Government to improve the development of multigrade education solutions. The CMGE was approved as a self-governing and funded entity of South Africa's Cape Peninsula University of Technology (CPUT). An interna- 
tional conference of 110 delegates from senior education and civic society organisations from Botswana, Namibia, Nigeria, South Africa (seven of the nine provinces), Tanzania, Uganda, Zambia, Colombia, Iran, India, Sri Lanka, Greece and Australia met in Paarl, South Africa, to analyze international best practice in multi-grade education as a viable alternative to address millennium development goal 2 , in which by 2015, all children will have access to UPE. The delegates were addressed on the outcomes of successful multi-grade education interventions that have transformed the lives of millions of children in thousands of schools in Australia, Colombia, Greece, India, Sri Lanka, the Netherlands and the United Kingdom by world experts from these countries. The first world declaration to discourse on the subject of multi-grade education as a remedy to alleviating the marginalisation of rural communities through education was the Wellington declaration on multi-grade education. It was unanimously adopted by the delegates of the Southern African Multi-grade education conference on 24 March 2010. The world is finally becoming aware of the fact that multigrade teaching can make a significant difference in improving the chances of success for rural primary school children. It must be the way forward (8).

The present status of multigrade schools in the world: The invisibility of multigrade teaching in many countries is strengthened by the absence of educational statistics collected by national and international authorities. Neither UNESCO nor Commonwealth agencies and many Commonwealth countries, routinely collect information on the schools and classes in which multigraded teaching and learning is taking place (9). The concept of a multigraded or nongraded school is not new. There is a long history of both developing and developed countries attempting to meet the educational requirement of sparsely populated rural areas by grouping students of various ages, grades, and experience in a single classroom. In Finland, for instance, 70 percent of all primary pupils are enrolled in schools with less than three teachers. Iceland has an average enrollment of 50 students for all rural primary schools and one-fourth of the schools in countries such as Spain and Scotland have less than 50 students. The 'one-roomschool house' is still an important aspect of primary education in rural parts of the United States and Canada, and France has over 11,000 one-teacher schools. Multigrade and single teacher schools are even more common in many developing countries. China has approximately 420,000 multigrade schools, while Indonesia and Malaysia have 20,000 and 1,540 respectively. In Latin America, 22 percent of Mexican primary schools are 'unitary', and multigrade classrooms consist of $50 \%$ of the schools in Belize and 88 percent of the schools in Honduras. Five thou- sand of the 7,544 rural primary schools in Guatemala are classified as 'unitary' (3). In Peru there are approximately 21,500 primary multigrade schools, $95 \%$ of which are located in rural areas. Eighty nine percent (89\%) of the rural schools are multigrade schools, and 41,000 are teachers, or $69 \%$ of the total rural teaching force teach in rural primary schools with multigrade classrooms. In Sri Lanka about 1250 schools out of the 10,120 schools in the country have less than three teachers. Vietnam has 2,162 multigrade schools that merge $2,3,4$, or 5 different levels in a single classroom. The unfortunate reality is that these schools form the most neglected part of the education system. For most part, they are located in isolated, low-income rural areas, and generally have untrained teachers. The few trained teachers usually understand and use only 'monograde' pedagogy. National curriculum contents, teaching and learning materials and activities taught at schools are frequently designed for monograde classes. The result of untrained and inappropriately trained teachers, as well as lack of appropriate teaching learning materials, is that children in multigrade classrooms spend much of their time relearning material they already know or sit idle and boxed. While the world is becoming increasingly urbanized, multigrade schools will continue to be a reality for several years to come. Adequately meeting the requirements of children in multigrade classrooms will be essential for the achievement of quality education for all (10).

Multigrade teaching in Iran: Multigrade classrooms have been in Iranian education system since a long time ago. According to Iranian EFA national act, in 2004 - 2005 academic years, there are 47 thousand multigrade classrooms in which 1 million students are going for study (11).

Considering the climatic conditions and widespread economic situation in remote rural areas, we cannot neglect the establishment of multigrade classes in primary schools which do not benefit from the proper educational facilities. The population decline in rural areas due to migration of villagers to the cities, population growth decline and rising age of marriage reduced the students' population in schools of rural areas and as a result increased the number of multigrade classes. And only the elementary schools in populated villages and towns have had singlelevel classes. Based on the statistics of 2007 - 2008 academic years, there were approximately 63 thousand elementary schools in Iran of which more than 28 thousand are multigrade. In some instances, it can be seen that a class of 5 student with 5 different grades are coeducational, while in some other schools this number increases to 30 with 2 or 3 different grades and one person performs the task of both managing the school and also teaching one or two levels (12).

The use of information and communication technolo- 
gies (ICT) in the multigrade classes: ICT is the educational tool of the 21st century. Increasingly, it is embedded seamlessly in all social and technical development processes, e.g., e-commerce, e-agriculture, e-health and other e-based business transactions. Also, it is essential for e-education or ICT-enabled education systems in order to develop and prepare ICT-enabled workers to function professionally in ICT-enabled work places in our knowledge-driven society. Evidently, integrating ICT into the school systems is critical to prepare students for 21st century learning and working environments (1). ICT can be a powerful tool for both students attending multi-grade schools and educators teaching in such schools. It can be used to provide training to teachers in multi-grade methodologies and allow students to engage in innovative, participatory multi-grade learning activities (13). ICT-based educational resources in multigrade schools should aid students to work with other students with different ability levels, and learn from older students. The development of resources and the organization of learning activities involving ICT, follow this general aim. In the learning processes, ICT resources are of key importance in the progression of pedagogic renewal attained by the school system and by the multigrade schools in current years. ICT resources permit the multigrade teacher to heighten respect for diversity, which is so important in the multigrade classroom. Furthermore, the ICT resources permit for breaking the barriers and the endemic isolation of the multigrade school while they contribute to strengthening local traditions and specificities; that is to say, ICTs enable rural students to access the globalized world without losing their roots (14).

The research literature and background: research studies focusing on multigrade instruction, particularly in rural setting, are quite rare. In Asia and the pacific programme of educational innovation for development, it is mentioned that teachers working in multigrade schools have to organize their work in a way that the learners of different grades are purposefully engaged in their studies and activities. Limitations such as inadequate seating space or even blackboards however compound their engagement in teaching pursuits. The curriculum load is so heavy that teachers continue to be indecisive about what to teach and how to teach it. Their training is often inadequate. Arranging teaching-practice in one teacher one class teaching conditions is difficult and so the problems linger. Teachers need to know how to make wise use of the curriculum in order to cope with their multiple roles. They require appropriate teaching methodologies and advice on using the available time, space, material resources, talent, and local community. An important pre-requisite is that the teacher should have a good working experience of the primary school curriculum and the methodologies re- quired to implement it (15).

Miller has identified six instructional dimensions affecting successful multi-grade teaching. They are, classroom organization, classroom management and discipline, instructional organization and curriculum, instructional delivery and grouping, self-directed learning and peer tutoring. In the context of Nepal, the government has neither developed any basic requirements regarding the aforementioned dimensions, nor are they well addressed in multi-grade teacher training practices. In multi-grade or multi-class settings of instructional organization, teachers should spend more time on organizing and planning of instruction in order to maintain the continuity of students' learning, utilization of available resources in the classroom and promoting interactive, participatory and child centered learning in the classroom (16).

In a study on multi-grade teaching in Research centre for educational innovation and development of Tribhuvan University in Nepal, instructional environment of the classroom was considered as cleanness, adequacy of light and ventilation, and furniture (adequacy and appropriate size of desks and benches) in the classroom (17). Giannakos and Vlamos studied primary schools' educational system in small and isolated islands of Greece. The research was conducted in six small and isolated schools in Greece. The study field compared mulitigrade traditional teaching to webcast enhanced multigrade teaching. The educational webcast was deployed to 22 primary school students. The results of the study revealed that educational webcasts can have a useful contribution to multigrade primary schools students (18).

Accordingly, that little research has been done focusing on managing multigrade classes with emphasis on the role of technology; it is evident that survey in this field is one of the research needs. So this research was organized to examine the classroom management strategies of multigrade schools in the east of Mazandaran province. In order to investigate the aim of research, the main question is:

What are the classroom management strategies of multigrade schools?

\section{Methods}

This study was a descriptive survey. In this study, the effective classroom management strategies of multigrade classes from the perspective of school administrators and teachers in the eastern part of Mazandaran province were evaluated by conducting a questionnaire. The statistical population was 129 managers and teachers of whom 97 were selected as the subjects of the study by simple random sampling method based on Krejcie and Morgan's ta- 
ble. So the attendant should be one of the teachers or managers of multigrade schools of Neka, Behshahr or Galoogah city in Mazandaran province.

Initially, multiple schools were established. Then, after the explanation of the aim and importance of the study to administrators and teachers who was partipant in the study, they were asked to complete questionnaires.

Statistical population and sample, based on city of study are presented in Table 1 . The participants were 20 female and 74 male. Also based on teaching experience 52 persons were below 5 years, 32 were between 5 and 10 and 13 were 10 and above.

The data gathering tool: multigrade class management components were identified based on the theoretical studies and surveys. Based on extracted components from literature, researchers made a questionnaire. The questionnaire comprised questions related to demographic information and questions concerning the multigrade classroom management strategies with 34 close-ended questions on a Likert five point format which have the reliability of 0.90 . The face and content validity of questionnaire was verified by experts. The collected data were analyzed through Exploratory Factor analysis with Varimax rotation by using SPSS 22 in the acceptable significant level of $\mathrm{P}<$ 0.001 .

It should be mentioned that it was explained to participants that the confidentiality of information supplied by research subjects and the anonymity of respondents will be respected and information will only be used by researchers for the purposes of the research. So the research participants were guaranteed on protection of their privacy. It is necessary to mention that voluntary participation of respondents was considered by researchers in the study.

\section{Results}

The results from the survey of 97 school administrators and teachers who partook in this study are revealed in this section of the study. Factor analysis was used to evaluate the classroom management strategies in multigrade schools. To conduct the factor analysis, two sets of test including the Kaiser-Meyer and Olkin (KMO) and Bartlett's test were used to ensure adequate sampling and establish the fact that the matrix correlation is not zero in the population.

Table 2 illustrates that the range of KMO is equal to 0.711 indicating adequate sampling and by considering the significance level of $<0.001$, the Bartlett test revealed that the relationships found is assigned to the unrelated variables and therefore conducting the factor analysis with regard to the subject of relationship is justified. Also, the result of principal component analysis is illustrated in Table 3.

The Varimax rotation was used to ascertain the number of dimensions. To do this, the 34 components were categorized into ten factors as effective strategic factors in classroom management of a class. Five components (including: providing an interactive learning environment, providing a multi-purpose class at the school, teaching the learning and teaching strategies and students' sitting in traditional classrooms), were excluded from the analysis due to the fact that their factor loading were less than 0.5. The results for the other components are illustrated in Table 4. Figure 1 showed the Scree Plot.

\subsection{Classroom Management Strategies Derived from Varimax Rotation}

The four components of the first factor have the highest relation to the locations and spaces in the classroom. Therefore, this factor was named as using classroom spaces and the strategies derived from the Varimax rotation for this factor include:

- Assigning a place for restoring and archiving the hand-made tools

- Providing a place for science or nature site

- Assigning a place as the discovery table

- Providing a place for displaying the educational tools and aiding tools

Four components including the second factor are more concentrated on the environment and content changes. Therefore, this factor is named as flexibility, and strategies resulting from the Varimax rotation include:

- Students' grouping

- Variable arrangement of tables and benches

- Book content change with climatic conditions

- Providing a serene environment away from the internal and external noise

The two constituents of the third factor are related to the software and hardware technology which is named as application of software and hardware technologies and the strategies obtain from the Varimax rotation include:

- Using new technologies such as computers,

- Using instructional design such as lesson plans

The four components including the fourth factor is the organization of the learning environment by the teacher. As a result, this factor is named as the organizing learning environment and the strategies taken from the Varimax rotation for this factor include:

- Using all the walls of the classroom

- Combining the adjacent levels and grades in one class

- Providing a place for displaying the educational aid tools 
Table 1. Statistical Population and Sample, Based on City of Study

\begin{tabular}{|c|c|c|c|c|}
\hline Province & City & Statistical Population & Sample & Percent \\
\hline \multirow{4}{*}{ Mazandaran } & Neka & 79 & 59 & 60.82 \\
\hline & Behshahr & 42 & 32 & 32.98 \\
\hline & Galoogah & 8 & 6 & 6.18 \\
\hline & Total & 129 & 97 & 100 \\
\hline
\end{tabular}

Scree Plot

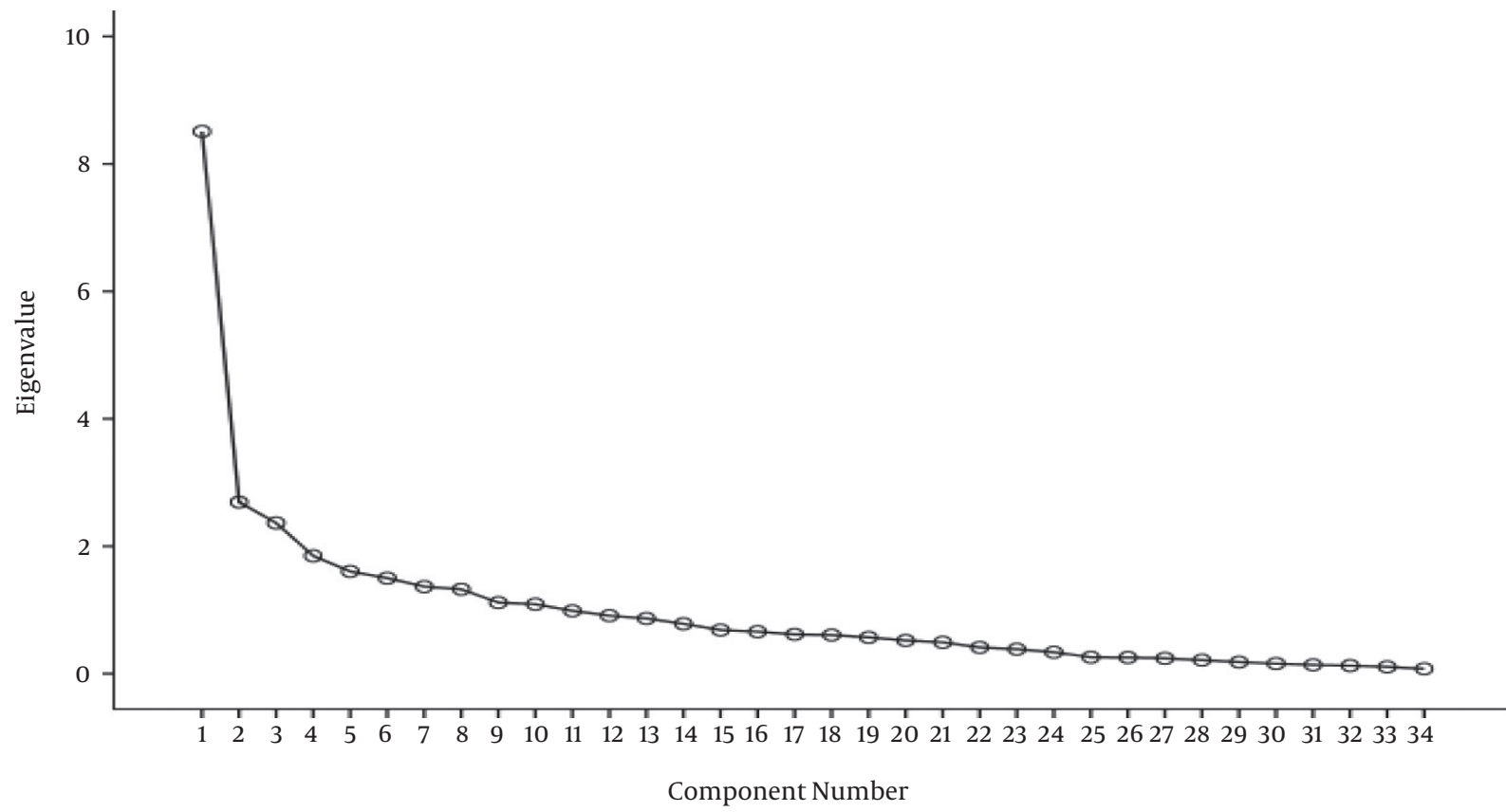

Figure 1. Scree Plot

Table 2. KMO and Bartlett's Test

\begin{tabular}{ccc}
\hline \multicolumn{2}{c}{ Kaiser-Meyer-Olkin Measure of Sampling Adequacy } & 0.711 \\
\hline Bartlett's Test of Sphericity & Approx. Chi-Square & 1342.244 \\
& df & 561 \\
& Sig. & 0.000 \\
\hline
\end{tabular}

- Assigning a space for the laboratory

The fifth factor is comprised three components for the evaluation. Therefore, this factor is named as evaluation and the strategies derived from the Varimax rotation include:

- Using a qualitative approach to evaluation

- Using the team evaluation

- Establishing a quantitative assessment approach
The components comprising the sixth factor include three components which are related to the appropriate teaching methods for multigrade classes and are therefore named as appropriate teaching methods and the strategies derived from the Varimax rotation include:

- Using the synthetic techniques

- Using pivotal techniques

- Using active teaching techniques

Concerning the three components of the seventh factor on the educational tools and aiding tools used by the teacher, this factor is named as educational tools, and the strategies developed from the Varimax rotation include:

- Using multiple blackboards

- Using the educational tools and aiding tools

- Using the electronic folders

The two components of the eighth factor are related to the division of tasks and the delegating of authority, there- 
Table 3. Total Variance Explained ${ }^{\mathrm{a}}$

\begin{tabular}{|c|c|c|c|c|c|c|c|c|c|}
\hline \multirow[t]{2}{*}{ Component } & \multicolumn{3}{|c|}{ Initial Eigenvalues } & \multicolumn{3}{|c|}{ Extraction Sums of Squared Loadings } & \multicolumn{3}{|c|}{ Rotation Sums of Squared Loadings } \\
\hline & Total & $\%$ of Variance & Cumulative \% & Total & $\%$ of Variance & Cumulative \% & Total & $\%$ of Variance & Cumulative \% \\
\hline $\mathbf{1}$ & 8.509 & 25.028 & 25.028 & 8.509 & 25.028 & 25.028 & 3.361 & 9.884 & 9.884 \\
\hline 2 & 2.692 & 7.918 & 32.946 & 2.692 & 7.918 & 32.946 & 2.816 & 8.283 & 18.167 \\
\hline 3 & 2.366 & 6.958 & 39.904 & 2.366 & 6.958 & 39.904 & 2.567 & 7.551 & 25.718 \\
\hline 4 & 1.849 & 5.438 & 45.343 & 1.849 & 5.438 & 45.343 & 2.549 & 7.497 & 33.215 \\
\hline 5 & 1.605 & 4.720 & 50.063 & 1.605 & 4.720 & 50.063 & 2.415 & 7.103 & 40.318 \\
\hline 6 & 1.499 & 4.409 & 54.471 & 1.499 & 4.409 & 54.471 & 2.392 & 7.034 & 47.352 \\
\hline 7 & 1.367 & 4.019 & 58.491 & 1.367 & 4.019 & 58.491 & 2.089 & 6.144 & 53.496 \\
\hline 8 & 1.325 & 3.898 & 62.389 & 1.325 & 3.898 & 62.389 & 2.030 & 5.970 & 59.465 \\
\hline 9 & 1.116 & 3.282 & 65.671 & 1.116 & 3.282 & 65.671 & 1.649 & 4.851 & 64.316 \\
\hline 10 & 1.090 & 3.207 & 68.878 & 1.090 & 3.207 & 68.878 & 1.551 & 4.562 & 68.878 \\
\hline
\end{tabular}

${ }^{a}$ Extraction method: principal component analysis.

Table 4. Rotated Component Matrix

\begin{tabular}{|c|c|c|c|c|c|c|c|c|c|c|}
\hline \multirow[t]{2}{*}{ Components } & \multicolumn{10}{|c|}{ Factors } \\
\hline & 1 & 2 & 3 & 4 & 5 & 6 & 7 & 8 & 9 & 10 \\
\hline Assigning a place for restoring and archiving the hand-made tools & 0.820 & & & & & & & & & \\
\hline Providing a place for science or nature site & 0.785 & & & & & & & & & \\
\hline Assigning a place as the discovery table & 0.709 & & & & & & & & & \\
\hline Providing a place for showing the educational tools and aiding tools & 0.622 & & & & & & & & & \\
\hline Students' grouping & & 0.825 & & & & & & & & \\
\hline Variable arrangement of tables and benches & & 0.761 & & & & & & & & \\
\hline Book content change with climatic conditions & & 0.596 & & & & & & & & \\
\hline Providing a quiet environment away from the internal and external noise & & 0.550 & & & & & & & & \\
\hline Using new technologies such as computers & & & 0.865 & & & & & & & \\
\hline Using instructional design such as lesson plans & & & 0.672 & & & & & & & \\
\hline Using all the walls of the classroom & & & & 0.762 & & & & & & \\
\hline Mixing the adjacent levels and grades in one class & & & & 0.744 & & & & & & \\
\hline Providing a place for showing the educational aid tools & & & & 0.602 & & & & & & \\
\hline Assigning a space for the laboratory & & & & 0.561 & & & & & & \\
\hline Using a qualitative approach to evaluation & & & & & 0.751 & & & & & \\
\hline Using the team evaluation & & & & & 0.644 & & & & & \\
\hline Establishing a quantitative assessment approach & & & & & 0.503 & & & & & \\
\hline Using the synthetic techniques & & & & & & 0.713 & & & & \\
\hline Using pivotal techniques & & & & & & 0.626 & & & & \\
\hline Using active teaching techniques & & & & & & 0.543 & & & & \\
\hline Using multiple blackboards & & & & & & & 0.772 & & & \\
\hline Using the electronic folders & & & & & & & 0.611 & & & \\
\hline Using the educational tools and aiding tools & & & & & & & 0.555 & & & \\
\hline Peers' education and training & & & & & & & & 0.822 & & \\
\hline Using assistant teachers & & & & & & & & 0.796 & & \\
\hline Having experience and work records of teaching multigrade classes & & & & & & & & & 0.690 & \\
\hline Ability in establishing verbal and nonverbal communication. & & & & & & & & & 0.607 & \\
\hline Painting the walls with relaxing colors & & & & & & & & & & 0.799 \\
\hline Using other spaces than the classrooms & & & & & & & & & & 0.631 \\
\hline
\end{tabular}

fore, it is named as delegation of authority and the strategies achieved from the Varimax rotation include:

\section{- Peers' education and training}

\section{- Using assistant teachers}

Factor nine includes two components associated with professional experience of teachers and are assigned as 
teachers' professional experiences and the derived strategies from the varimax rotation include:

- Having experience and work records of teaching multigrade classes

- Ability to establish verbal and nonverbal communication

The two components of the tenth factor are named as enlivening the learning environment because it talks about the provision of a pleasant and lively interplay of learning environment for students which is named as the enlivening the learning environment and its obtained strategies on the Varimax rotation include:

- Painting the walls with relaxing colors

- Using other spaces than the classrooms

\section{Discussion and Conclusions}

Findings of the research revealed ten strategies for managing multigrade classrooms. The first factor was using classroom spaces. The efficient classroom is a center of learning activities. Furniture and materials in the classroom should directly support the types of learning that occur in (19). The arrangement of tables and benches in the classroom and taking advantage of using all walls, ceiling and floor in a classroom will significantly influence the teachers and students' performance.

The second factor was flexibility. Berry mentioned that managing a multigrade classroom is difficult because there is more than one grade level in the classroom. Hence, the teacher must be skilled in managing instruction to reduce the amount of 'dead time' during which children are not productively engaged on task. This implies that teachers must be aware of different ways of grouping children, the importance of independent study areas where students can go when they are through with their work, and approaches to record keeping which are more flexible than those common in the monograde classroom (4). The flexibility that is intrinsic in the organisation of the multigrade school is an essential aspect in the context of developing countries. It helps to address wastage, e.g. absenteeism, repeating and drop-out rates. In a school where multiple grades are taught simultaneously in one class period, and/or the curriculum is delivered over multiple (probably two) yearly spans, the opportunities for students to re-enter after a stop-out period by removing the stigma attached to working below grade level on re-entry are greatly enhanced. A benefit of this flexibility is that it helps to keep students motivated and capable of achieving results at their own pace (20).

The third factor was application of software and hardware technologies. As Chouhan believed, information and communication technology can be a powerful tool for both students and their teachers in multi-grade schools and permits students to engage in innovative, participatory multi-grade learning activities. ICT-based educational resources in multigrade schools should help students to work with other students with different levels of ability and learn from older students (13). Giannakos and Vlamos revealed that educational webcasts can have an important contribution to multigrade primary schools students (18).

The fourth factor was organizing learning environment. Sufficient time for planning must be available to meet the requirements of both teacher and learner. Insufficient planning, staff development, materials, support and assessment will have an impact on the success of the multigrade programme $(21,22)$. The multigrade classroom is a fishbowl where everything can be heard and seen. The teacher has to be aware of this privilege and act accordingly; the challenge is in the application of interdisciplinary and/or globalized methodologies that are established particularly on diversity, in an open and flexible space/time. Its application is based on a contemporary view of pedagogy in which new strategies are employed and dialog, collaboration, and critical thought, as well as proposition and solution of problems related to the several knowledge branches are promoted (14).

The fifth factor was evaluation. The evaluation of the learning outcomes of the different students found in multigrade classroom is not always easy (1). Evaluation is the process of reviewing progress against the background of stated objectives. It is very easy to loose control of class if student's behavior in class is not properly monitored. Keeping records is very useful, and of great help to the teacher and to people in need of information, about the class. And finally, performing evaluation helps to monitor pupils' progress. Monitoring, keeping records of pupils'progress and evaluation are very important, particularly in multi-grade teaching, because of the different levels of work going on at the same time. They are what make the tasks manageable (23).

The sixth factor was appropriate teaching. One of the most important factors which will help to provide opportunities for effective teaching is classrooms organizations. If the classroom is not properly organized, it will be unsuccessful even if a sophisticated lesson plan is provided. A multigrade classroom teacher is required to both organize the lesson course and also organize and manage the physical space of the class. Multigrade classroom teachers should be totally aware of the abilities and basic natural curiosity of students and based on these characteristics of their students, they are to design suitable learning activities to offer to the students in order to meet their educational requirements.

The seventh factor was educational tools. While the in- 
formation and communication technologies is penetrating within the rural remote areas where most of the multigrade schools are located, the class management and organization strategies have to be reevaluated in order to take advantage of the use of software tools such as virtual classrooms and communication channels like satellite links (14). Teaching aids include a wide variety of electronic, printed, visual and audio-visual materials, as well as computers, which can be used to present the concepts graphically in order to aid the teaching/learning process (23).

The eighth factor was delegation of authority. Parental participation has also been encouraged in a range of activities such as conducting learning exercises with children (often with the knock-on effect of providing basic education skills to parents), working as community teachers and advocates (specifically in terms of health and hygiene practices), providing help in the organization of classrooms and schools, and helping teachers in preparing teaching aids. Active community involvement in these areas can be a highly positive resource and can have significant impacts on children's learning achievements, health and welfare (24).

The nineth factor was teachers' professional experiences. One of the issues in multigrade classrooms has been the degree of implementation of programs, particularly those in which a change in teacher's attitudes and practices is required. It has been shown that even in a program that is considered to be highly successful, there is still variation in teaching methods across the classrooms (25). Efficient use of class time to improve and possibly prevent academic failure and diagnosing the destructive factors is important to such classrooms. The multigrade classes should incorporate different levels so that teachers will have sufficient time to address all individual's courses and needs and focus on individual differences at all stages of the teaching (26). The multigrade classes and their associated problems necessitate the need to use the proper time and place for teachers. Since having access to better quality education and equal educational opportunity is the natural rights of every individual to be considered, the teachers' role in making a better use of the available positions are emphasized. Classrooms and educational settings provide lots of opportunities for acquiring a good teaching result. Teachers who are interested and aware of these situations can help create the conditions which can be used to improve students' learning and recognizes the fact that his/her behaviors and decisions are effective.

The tenth factor was enlivening the learning environment. In a study on multi-grade teaching in Nepal, instructional environment of the classroom was considered as cleanness, adequacy of light and ventilation, and furniture in the classroom (17). Mathot believed that in order to create a good working atmosphere, the whole environment must be conducive. The classroom must be well organized, clean and pleasant, displays pupils' work on the walls and make the activity centres attractive (23).

Multigrade teaching is not always easy, but carrying it out properly implies that you are educating children who otherwise would be unable to go to school and therefore helping them gain the knowledge and skills they require for a more promising future (1). Working in an open, multigrade school requires serious, ongoing teacher training and a commitment to hard work. Most teachers receive training for teaching single grade classrooms organized around the whole-class and/or small ability-grouped instruction. When placed in an open, multigrade setting, teachers discover that the time requirements and skills needed to be effective are simply not part of their training and experience. In addition, a long tradition of graded schools has created powerful expectations for administrators, teachers and parents concerning how school should be organized (27).

Classroom Management is considered to be highly significant in multigrade classroom education. It is clearly defined as to forecast and predict the need to create and maintain an environment in which teaching and learning are integrated. The primary objective of an effective classroom management is not just reducing the mistreatment or creating an expected customary environment. Providing exercises and activities that would make students passive and maintain the order in the class does not indicate enhance learning opportunities. It's the opposite that these conditions reduce learning opportunities which should be taken into account in the multigrade classes since students have to go through a passive state in most of their class time to enable the teacher teach other students with higher or lower grades or they will be asked to read their books or perform other in-class activities but there is no control or supervision on the classes and activities and students will not be monitored and managed; the classrooms are quiet and orderly, however they do not increase the amount of learning which should be noted since the basic and primary reason for the effective classroom management is learning or increasing students' learning.

\section{Acknowledgments}

We would like to thank all those teachers and managers who have contributed to the research. We would also like to thank anonymous reviewers for critical comments that greatly strengthened the manuscript. 


\section{Footnotes}

Authors' Contribution: All authors contributed extensively to the work presented in this paper. Farshideh Zameni and Mousa Movahedian developed the concept and designed the study. Mousa Movahedian and Taraneh Enayati collected and analyzed data. Taraneh Enayati drafted the manuscript and worked to prepare the manuscript with Farshideh Zameni. All authors read and approved the final manuscript.

\section{Conflict of Interest: None declared.}

\section{References}

1. UNESCO . Embracing Diversity: Toolkit for Creating Inclusive, Learning-Friendly Environments Specialized Booklet 4, Practical Tips for Teaching Multigrade Classes. UNESCO Bangkok Asia and Pacific Regional Bureau for Education; 2013.

2. Little A. Multigrade teaching: a review of practice and research. London: Overseas Development Administration; 1995.

3. Juárez and Associates Inc . The effects of active learning programs in multigrade schools on girls' persistence in and completion of primary school in developing countries. USAID Bureau of Economic Growth, Agriculture, and Trade, Office of Women in Development; 2003.

4. Berry C. Multigrade teaching: A discussion document. AWorkshop held by the Commonwealth Secretariat. ; 2000.

5. Little AW. Multigrade teaching: towards an international research and policy agenda. Int J Educ Dev. 2001;21(6):477-9. doi: 10.1016/s07380593(01)00010-4.

6. Mulkeen AG, Higgins C. Multigrade Teaching in Sub-Saharan Africa: Lessons from Uganda, Senegal, and the Gambia. World Bank Publications; 2009.

7. Little AW. Learning and teaching in multigrade settings; Unpublished paper prepared for the UNESCO. ;2005.

8. Joubert J. Multi-grade teaching in South Africa. Common Wealth Education Online. ; 2010

9. Little AW. Access and achievement in Commonwealth countries: support for learning and teaching in multigrade classrooms. Commonwealth Education Partnerships. ; 2004.

10. Wolf L, García N. Multi-grades Schools and Technology. InterAmerican Development Bank. TechKnowLogia; 2000.

11. Aghazadeh M, Ataran M, Farzad V, Haji HGR. Designing and validating of national curriculum adaptation model for multi-grade classrooms. J Curriculum Stud. 2007;2(6):9-32.
12. Soleimani N, Hadadian A, Shahrabi K. Comparative study of academic achievement and social skills of students in multigrade and ordinary classes in primary schools. J Educ Leadersh Administ. 2011;4(4):129-44.

13. Chouhan T. Multi-grade and multi class teaching practice in Nepal. Blacksburg's Virginia United state of America: The inn at Virginia teach \& skeleton conference center; 2015.

14. Tsolakidis C, Sotiriou S, Koulouris P. Lifelong e-learning for multigrade school teachers. Proceedings of the First Workshop of the Network of Multigrade Education (NEMED). ; 2005.

15. UNESCO/APEID . Multigrade teaching in single teacher primary schools: Asia and the Pacific Programme of Educational innovation for Development. UNESCO Principal Regional Office for Asia and the Pacific Bangkok; 1989.

16. Miller B. Teaching and Learning in the Multigrade Classroom: Student Performance and Instructional Routines. ERIC Digest. ERIC Clearinghouse; 1991

17. Tribhuvan University . A study on multi-grade/multi-class teaching Status and issues. Nepal: Research Centre for Educational Innovation and Development; 2003.

18. Giannakos MN, Vlamos P. Using educational webcasts in small multigrade schools of isolated islands. Int JEduc Dev Using Inf Commun Technol. 2012;8(2):131

19. Vincent S. The Multigrade Classroom: A Resource Handbook for Small, Rural Schools. Book 4: Instructional Organization, Curriculum, and Evaluation. ; 1999.

20. Rowley SD, Nielsen HD. School and Classroom Organization in the Periphery. New York: Garland Publishing; 1997.

21. Miller BA. Children at the Center: Implementing the Multiage Classroom. ERIC; 1994.

22. Nye BA. Are multi-grade programmes providing students with a quality education? Some answers from the school success study. Paper Presented at the Annual Conference on Creating Quality Schools. ; 1995.

23. Mathot G. A handbook for teachers of multigrade classes. UNESCO; 2001.

24. Blum N, Diwan R. Small, multigrade schools and increasing access to primary education in India: National context and NGO initiatives. 2007.

25. Benveniste LA, McEwan PJ. Constraints to implementing educational innovations: The case of multigrade schools. Int Rev Educ 2000;46(1/2):31-48. doi: 10.1023/a:1003922321999.

26. Azizi B. Multigrade, How many children: Some solutions of a multigrade class teacher for problems and Optimization of the classes. Growth Elementar Educ. 2009;13(3):22-3.

27. Miller BA. A Review of the Qualitative Research on Multigrade Instruction. Res Rural Educ. 1990;7(1):1-8. 